Nur Hidayah ${ }^{1}$, Arlina Dewi ${ }^{2}$

PProgram Studi Magister Administrasi Rumah Sakit, Program Pascasarjana, Universitas Muhammadiyah Yogyakarta Jalan Brawijaya, Tamantirto, Kasihan, Bantul, Daerah Ismiewa Yogyakarta 55183

Email: nurhidayah@umy.ac.id

\section{Pemetaan Analisis Jabatan dan Penilaian Kinerja sebagai Dasar Pengembangan Sistem Remunerasi}

\author{
10.18196/berdikari.v9i1.6500
}

\begin{abstract}
Job analysis and performance appraisals are the basis of developing a remuneration system consisting of fees for position, fees for service, and fees for people. Clinic Pratama receives payment for health services for patients participating in the National Health Insurance in the form of a capitation package. The capitation package distribution has not been regulated based on the position value index and performance appraisal according to the performance indicators of each employee's detailed job descriptions, responsibilities and authorities. The purpose of this community service activity is to develop a remuneration system which can then be implemented in KPF as a strategy in human resource management facing the era of National Health Insurance (JKN) to achieve Universal Health Coverage (UHC). The method used is a qualitative method through a Focus Group Discussion (FGD) approach, interviews and documentation studies. The results of community service show that the Remuneration System can be developed based on Job Analysis and Performance Appraisals

Keywords: Job Analysis, Performance Appraisal, Remuneration, Pratama 24-hour Firdaus Clinic (KPF)
\end{abstract}

\title{
ABSTRAK
}

Analisis Jabatan dan penilaian kinerja menjadi dasar dari pengembangan sistem remunerasi yang terdiri dari fee for position, fee for service, dan fee for people. Klinik pratama mendapatkan pembayaran jasa pelayanan kesehatan untuk pasien peserta Jaminan Kesehatan Nasional dalam bentuk paket kapitasi. Di dalam paket Kapitasi tersebut, belum diatur pembagiannya berdasarkan indek nilai jabatan dan penilaian kinerja berdasarkan indikator kinerja setiap pegawai berdasarkan uraian tugas, tanggungjawab, dan wewenangnya secara rinci. Tujuan dari kegiatan pegabdian masyarakat ini adalah mengembangkan sistem remunerasi untuk kemudian dapat diimplementasikan di KPF sebagai strategi dalam manajemen sumber daya manusia menghadapi era Jaminan Kesehatan Nasional (JKN) untuk mencapai Universal Health Coverage (UHC). Metode yang digunakan adalah metode kualitatif melalui pendekatan Focus Group Discussion (FGD), wawancara, dan studi dokumentasi. Hasil pengabdian kepada masyarakat menunjukkan bahwa Sistem Remunerasi dapat dikembangkan berdasarkan analisis jabatan dan penilaian kinerja. Keywords: Analisis Jabatan, Penilaian Kinerja, Remunerasi, Klinik Pratama 24 jam Firdaus (KPF). 


\section{PENDAHULUAN}

Sebagai salah satu Fasilitas Kesehatan Tingkat Pertama (FKTP), Klinik Pratama 24 Jam Firdaus (selanjutnya disebut KPF) tentunya telah merumuskan visi dan misi sebagai pedoman dalam mencapai kinerja terbaik dalam memberikan jasa pelayanan kesehatan bagi pasien. Adapun visi Klinik Pratama 24 Jam Firdaus yaitu "menjadi center of excellence untuk pelayanan, pendidikan dan penelitian bidang kesehatan layanan primer di Indonesia pada tahun 2025”. Disamping itu, untuk mencapai visi tersebut, maka KPF menetapkan 2 Misi yang terdiri dari; 1. Providing high quality of primary health care (menyediakan pelayanan kesehatan primer yang berkualitas tinggi sesuai standar global untuk meningkatkan status kesehatan pasien); dan 2. Menjadi wahana kegiatan pendidikan dan penelitian bagi profesi dokter dan tenaga kesehatan lain di tingkat layanan primer yang unggul dan Islami. Adapun moto dari KPF yaitu "Care, Comfort, Wellness". Dalam rangka mencapai Visi dan Misi KPF serta mempertahankan prestasinya, maka dibutuhkan adanya sumber daya manusia (SDM) yang berkualitas. SDM tersebut mempunyai pengetahuan yang luas dan keterampilan sesuai dengan bidangnya, serta sikap dan perilaku yang tanggap terhadap perubahan lingkungan terutama kebutuhan pasien. Hal tersebut mengingat SDM memegang peranan penting dalam organisasi manapun (Lowe, 2012; Negrut et al., 2015), tak terkecuali dalam organisasi pelayanan kesehatan seperti KPF. Untuk itu, demi mewujudkan SDM yang berkualitas, dibutuhkan adanya pelatihan yang profesional (Negrut et al., 2015). Pelatihan-pelatihan yang sesuai dengan kebutuhan pelayanan kesehatan yang dipengaruhi faktor lingkungan eksternal yang sangat dinamis dan mengalami perubahan yang sangat cepat dari waktu ke waktu. Sumber daya manusia KPF menjadi kekuatan andalan untuk meraih peluang agar mampu bersaing secara positif dan berkelanjutan, serta mencapai kinerja organisasi yang tinggi (Bednall et al., 2014; Shammot, 2014) yang memberikan nilai bermakna bagi pasien dan keluarganya, organisasi KPF dan sumber daya manusia, serta masyarakat sebagai pemangku kepentingan KPF.

Kinerja yang tinggi perlu diberi penghargaan baik finansial maupun nonfinansial. Penghargaan mempunyai hubungan positif dan signifikan terhadap kinerja karyawan (Prabu \& Wijayanti, 2016). Penghargaan cenderung dapat meningkatkan prestasi kerja karyawan (Aggarwal \& Thakur, n.d.) yang memberikan dampak baik terhadap kinerja karyawan. Selain itu, Penghargaan berpengaruh langsung dan tidak langsung terhadap kinerja melalui motivasi kerja (Fajar et al., 2018). Salah satu bentuk penghargaan yang signifikan berpengaruh terhadap kinerja adalah remunerasi. Remunerasi berpengaruh terhadap kepuasan kerja, kepuasan kerja berpengaruh terhadap loyalitas pegawai dan 
komitmen pegawai tehadap organisasi (Berliana et al., 2018). Kepuasan kerja akan meningkakan produktivitas pada sebuah organisasi, kemudian akan meningkatkan kinerja organisasi secara keseluruhan (Berliana et al., 2018). Kompensasi memegang peranan penting di dalam menentukan tingkat kepuasan pegawai (Asegid et al., 2014). Sistem remunerasi adalah bagian dari kompensasi yang berbentuk finansial. Sistem remunerasi dapat dijadikan strategi sebagaimana kompensasi. Ada 5 hal yang dapat menentukan efektivitas dari kompensasi sebagai strategi, yaitu (Chang et al., 2017):

1. Mendukung strategi secara keseluruhaan;

2. Menghargai perilaku pegawai yang bernilai;

3. Menawarkan kompensasi secara individual;

4. Membawa perhatian pada kompensasi secara total; dan

5. Mengakui Return on Invesment (ROI) dengan kompensasi yang berupa uang.

Remunerasi mendukung strategi secara keseluruhan artinya kinerja pegawai diukur dengan pencapaian dan target yang ditetapkan organisasi, sehingga pegawai diarahkan untuk memberikan kontribusi pada pencapaian tujuan organisasi. Untuk mencapai tujuan organisasi diperlukan strategi, maka strategi kompensasi merupakan bagian dari strategi secara keseluruhan. Perilaku pegawai yang bernilai artinya perilaku pegawai tersebut mengarah pada pencapaian nilai organisasi secara keseluruhan. Perilaku yang menyimpang dari tujuan organisasi berarti tidak bernilai. Perilaku yang bernilai perlu mendapatkan penghargaan sepantasnya. Remunerasi ditawarkan secara individual artinya tergantung pada pencapaian individu masing-masing dalam meraih sasaran yang sudah ditetapkan. Membawa perhatian pada remunerasi secara total artinya memperhatikan seluruh kebutuhan sebagaimana dijelaskan oleh Maslow dengan hirarki kebutuhan, yaitu kebutuhan fisiologis, rasa aman, sosial, penghargaan dan aktualisasi diri (Maslow \& Frager, 1987).

Klinik Pratama 24 Jam Firdaus (selanjutnya disebut KPF) merupakan salah satu Fasilitas Kesehatan Tingkat Pertama (FKTP) yang sudah berdiri sejak 2 Mei 2015. Setelah satu bulan didirikan, KPF langsung bekerjasama dengan Badan Penyelenggara Jaminan Sosial (BPJS), tepatnya sejak 1 Juni 2015. Seiring dengan perjalanannya, KPF terus mengalami perkembangan yang sangat pesat. Hal tersebut dibuktikan dengan adanya pencapaian yang telah diraih oleh KPF diantaranya yaitu; 1) Menjadi juara pertama sebagai Klinik Berprestasi di Wilayah Daerah Istimewa Yogyakarta pada tahun ketiga sejak didirikannya KPF; dan 2) Menjadi juara ketiga sebagai Klinik Berprestasi Tingkat Nasional. Selain itu, KPF juga telah mendapatkan reakreditasi. Hal tersebut sebagai salah satu komitmen KPF dalam menjaga dan mempertahankan mutu pelayanan dan kepuasan pelanggan. 
KPF telah memberikan pelayanan rawat jalan 24 jam dengan manajemen pelayanan kesehatan klinik yang baik dan sudah diakui oleh masyarakat dan pemangku kepentingan lainnya. Namun, seiring dengan adanya kemajuan pengetahuan dan teknologi serta perubahan lingkungan yang sangat pesat, KPF perlu untuk terus melakukan upaya peningkatan kinerja sumber daya manusia (SDM) secara berkelanjutan. Dengan demikian, KPF perlu menemukan strategi yang dapat memberikan motivasi dan meningkatkan produktivitas SDM. Adapun salah satu strateginya yaitu dengan memberikan penghargaan melalui remunerasi. Saat ini KPF telah menggunakan sistem remunerasi yang terdiri dari fee for position, fee for performance, dan fee for people. KPF mendapatkan pembayaran jasa pelayanan kesehatan yang diberikan kepada pasien dalam bentuk paket kapitasi berdasarkan jumlah anggota masyarakat dalam lingkup pelayanan klinik yang menjadi peserta Jaminan Kesehatan Nasional (JKN). Di dalam paket Kapitasi tersebut, belum diatur pembagiannya berdasarkan indek nilai jabatan dan penilaian kinerja berdasarkan indikator kinerja setiap pegawai berdasarkan uraian tugas, tanggungjawab, dan wewenangnya secara rinci. Berdasarkan permasalahan yang dihadapi KPF tersebut, program pegabdian masyarakat ini bertujuan untuk meyusun dan mengembangkan sistem remunerasi untuk kemudian diimplementasikan di KPF sebagai strategi dalam manajemen SDM menghadapi era Jaminan Kesehatan Nasional (JKN) untuk mencapai Universal Health Coverage (UHC). Adapun solusi yang ditawarkan dalam mengatasi permasalahan tersebut, yaitu dengan melaksanakan analisis jabatan dan penilaian kinerja yang kemudian hasil evaluasinya menjadi dasar dalam merumuskan sistem remunerasi.

\section{METODE PELAKSANAAN}

Program pengabdian masyarakat ini bertempat di Klinik Pratama 24 Jam Firdaus Yogyakarta (KPF). Metode yang digunakan dalam kegiatan pengabdian masyarakat ini, yaitu metode kualitatif melalui pendekatan Focus Group Discussion (FGD), wawancara, dan studi dokumentasi. Pelaksanaan kegiatan pengabdian masyarakat ini dilakukan dengan cara; 1) Memberikan penyuluhan kepada Manajer KPF terkait pengembangan sistem remunerasi untuk Klinik; dan 2) Menyampaikan kuisioner untuk menyusun analisis jabatan yang kemudian hasil dari analisis jabatan dapat digunakan sebagai pedoman penilain kinerja individu pegawai. Dalam pelaksanan program kegiatan pengabdian masyarakat ini, mitra juga berpartisipasi aktif dalam memberikan masukan saat FGD, memberikan informasi yang diperlukan saat wawancara, mengisi kuisioner, serta memberikan informasi dari dokumen yang diperlukan. Dengan demikian, dari 
data kuisioner tersebut menunjukkan bahwa ada 24 jabatan yang terdapat di KPF. Kemudian, data tersebut dapat digunakan untuk penilaian kinerja individu pegawai sebagai dasar dasar dari pengembangan sistem remunerasi.

Tabel 1. Jabatan-Jabatan Yang Dianalisis

\begin{tabular}{llcc}
\hline No & Jabatan & Jumlah Jabatan & Persen \\
\hline 1 & Manajer Pelayanan & 1 & $4 \%$ \\
2 & Ketua Tim Mutu & 1 & $4 \%$ \\
3 & Dokter & 4 & $17 \%$ \\
4 & Dokter Gigi & 1 & $4 \%$ \\
5 & Perawat & 5 & $21 \%$ \\
6 & Perawat Gigi & 2 & $8 \%$ \\
7 & Apoteker & 2 & $8 \%$ \\
8 & Assisten Apoteker & 2 & $8 \%$ \\
9 & Bidan & 2 & $8 \%$ \\
10 & Administrasi Keuangan/keuangan & 1 & $4 \%$ \\
11 & Umum & 2 & $8 \%$ \\
12 & Penanggungjawab Pelayanan Mahasiswa UMY & 1 & $4 \%$ \\
Jumlah Total Jabatan & 24 & $100 \%$ \\
\hline
\end{tabular}

\section{HASIL DAN PEMBAHASAN}

\section{Hasil Analisis Data}

Dalam penyusunan sistem remunerasi, langkah awal yang perlu dilakukan adalah melakukan analisis jabatan yang kemudian hasil dari analisi jabatan dapat digunakan sebagai pedoman untuk penilaian kinerja pegawai. Maka dari itu, dalam kegiatan pengabdian masyarakat ini dibagikan kuisioner dalam bentuk form analisis jabatan pegawai KPF. Adapun data dari hasil pengisian kuesioner dalam bentuk form analisis jabatan teridentifikasi sebagai berikut. (Lihat Tabel 1). Adapun Komponen Jabatan dalam Form Analisis jabatan adalah sebagai berikut. (Lihat Tabel 2)

Dari komponen form analisis jabatan terkait dengan kondisi lingkungan kerja, ratarata nilai adalah 8,3 dari skor 0 sampai dengan 10. Pada umumnya, pegawai KPF merasa nyaman di tempat kerja dengan penerangan yang baik, suhu ruangan bersih, sejuk dan dingin karena menggunakan ac, serta sirkulasi udara yang juga baik. Letak KPF strategis karena dekat jalan raya, tetapi efeknya kadang-kadang bising untuk posisi yang paling dekat dengan jalan dan di samping tempat parkir.

Risiko kerja atau bahaya bagi pegawai yang berhubungan dengan pasien langsung dapat tertular penyakit dari pasien yang mempunyai penyakit menular, tertusuk jarum, 
atau kaca ampul. Namun, hal itu disadari oleh petugas kesehatan untuk berhati-hati dan melindungi diri dari kemungkinan tertular penyakit dengan mencuci tangan secara benar dan menggunakan Alat Pelindung Diri (APD), serta memberikan edukasi kepada pasien dan keluarganya. Risiko-risiko khusus seperti risiko dokter gigi dan perawat gigi posisi saat memberikan pelayanan gigi yang memerlukan waktu lama dapat menyebabkan sakit tulang punggung dan leher. Dokter, bidan, perawat, apoteker, asisten apoteker juga masing-masing mempunyai risiku sebagai petugas kesehatan. Risiko kerja menjadi pertimbangan di dalam menentukan remunerasi. Saat ini, kebanyakan pegawai berurusan dengan komputer sebagai barang elektronik. Perkabelan perlu dirapikan dan diamankan untuk menghindari risiko tersetrum, serta tidak mengganggu estetika tempat kerja.

Tabel 2. Komponen Jabatan

\begin{tabular}{llll}
\hline No & Komponen Jabatan & NO & Komponen Jabatan \\
\hline 1 & Nama & 9 & $\begin{array}{l}\text { Korelasi Jabatan } \\
\text { Jabatan } \rightarrow \text { Unit kerja } \rightarrow \text { dalam hal }\end{array}$ \\
2 & Jabatan & 10 & $\begin{array}{l}\text { Kondisi/Lingkungan kerja } \\
\text { Aspek } \rightarrow \text { score } 1-10\end{array}$ \\
& & tempat kerja, Suhu, udara, keadaan ruangan, letak, \\
& & penerangan, suara, keadaan tempat kerja, getaran
\end{tabular}

Persyaratan jabatan yang harus dipenuhi terkait dengan remunerasi adalah pendidikan, pengalaman, keterampilan, dan pelatihan sesuai dengan tuntutat jabatan atau pekerjaannya. Adapun bakat dan minat diharapkan sesuai dengan profesi dan jabatannya, tetapi dalam kenyataannya tidak demikian. Minat dan bakat seni, olah raga, memasak, 


\section{3}

dan sebagainya dapat disalurkan melalui hobi di luar jam kerja sebagai variasi dalam kehidupan kerja. Pimpinan dan pegawai KPF semuanya masih relatif muda dalam usia yang produktif, sedangkan berat badan dan tinggi badan masih dalam batas normal.

\section{Pembahasan}

Klinik Pratama 24 Jam Firdaus (selanjutnya disebut KPF) merupakan salah satu industri yang bergerak dalam bidang pelayanan kesehatan kepada masyarakat berupa pelayanan rawat jalan untuk pasien umum dan pasien dokter gigi. Pelayanan yang diberikan berupa konsultasi dokter umum dan dokter gigi, tindakan-tindakan yang diperlukan untuk pasien sesuai dengan wewenang dokter umum dan dokter gigi, pelayanan penunjang seperti pelayanan pemeriksaan laboratorium dan farmasi. Selain tenaga medis, ada juga perawat yang bertugas memberikan perawatan kepada pasien rawat jalan sesuai dengan kebutuhan. Unit produksi didukung oleh manajemen KPF agar pelayanan dapat berjalan lancar karena ada pelayanan yang bersifat klinis ada juga yang sifatnya administratif/ manajerial. Ketika remunerasi tidak berjalan sebagaimana seharusnya, produksi jasa pelayanan kesehatan terganggu (Koziol \& Mikos, 2020). Oleh karena itu, diperlukan sistem remunerasi yang adil dan transparan (Datta, 2012), proporasional, dan dapat memotivasi pegawai untuk menghasilkan kinerja yang tinggi (Armstrong, 2018) dalam pelayanan kesehatan yang dilaksanakan oleh KPF.

Pengembangan sistem remunerasi terdiri dari beberapa tahap yang memerlukan waktu yang cukup lama, yaitu lebih dari satu tahun. Sistem remunerasi terdiri dari berbagai elemen diantaranya, strategi, kebijakan, praktik, proses, dan prosedur (Koziol \& Mikos, 2020). Tahap awal dari pengembangan sistem remunerasi dimulai dengan melaksanakan analisis jabatan dan penilaian kinerja sebagai dasar dari penyusunan dan pengembangan sistem remunerasi yang terdiri dari Fee for Position (penentuan gaji tetap), Fee for Performance (penentuan Insentif Kinerja), dan Fee for People (penentuan tunjangan-tunjangan). Analisis jabatan bertujuan untuk mendapatkan deskripsi dan spesifikasi jabatan untuk semua jabatan/pekerjaan yang ada di klinik secara lengkap, sehingga dapat dijadikan dasar acuan dari fungsi-fungsi manajemen sumber daya manusia yaitu perencanaan SDM, rekrutmen, seleksi, penempatan, pendidikan dan pelatihan, penilaian kinerja, pemberian kompensasi, pengembangan karir, hubungan antar pegawai (Waheed et al., 2016) (atasan dan bawahan serta sesama pegawai, dan hubungan antara pegawai dengan klinik).

Hasil dari analisis jabatan yang telah dilaksanakan di KPF diperoleh data bahwa terdapat 13 Jabatan di KPF yang terdiri dari; Manajer Pelayanan Kesehatan (dokter umum), Ketua Tim Penjamin Mutu, Dokter Umum, Dokter Gigi, Bidan, Perawat Umum, 
Apoteker Penanggungjawab Apotek (APPA), Apoteker Pendamping, Perawat Gigi, Asisten Apoteker, Administrasi Keuangan, Koordinator Umum, Penanggungjawab Dana Kesehatan Mahasiswa, Asisten Koordinator Umum (merangkap perawat). Semua Jabatan tersebut di bawah Pimpinan Klinik 24 Jam Firdaus, baik langsung maupun tidak langsung. Pimpinan Klinik pekerjaannya bersifat leadership dan manajerial, mengorganisir, mengkoordinir, dan mengarahkan semua sumber daya yang dimiliki klinik termasuk sumber daya manusianya untuk mencapai tujuan jangka pendek maupun tujuan jangka panjang sesuai dengan visi dan misi klinik. Kinerja Klinik Pratama 24 Jam Firdaus menjadi tanggungjawab pimpinan klinik yang tugas, tanggungjawab, dan wewenangnya sebagian dibagi habis (didelegasikan) kepada semua pemegang jabatan/pekerjaan. Semua laporan pertanggungjawaban pekerjaan disampaikan kepada pimpinan secara berjenjang sesuai dengan hierarki jabatan.

Setelah melaksanakan analisis jabatan, kemudian hasilnya dijadikan sebagai pedoman dalam penyusunan penilaian kinerja berdasakan masing-masing fungsi jabatan. Penilaian kinerja individu pegawai Klinik Pratama 24 Jam Firdaus yang sesuai dengan indikator kinerja berdasarkan tugas, wewenang, dan tanggungjawabnya perlu dilakukan dalam upaya untuk meningkatkan kinerja Klinik Pratama sebagai pemberi pelayanan kesehatan tingkat pertama kepada masyarakat. Tanpa adanya penilaian kinerja individu pegawai yang berbasis kinerja, sulit untuk mempertahankan kinerja Klinik Pratama yang selama ini sudah sangat baik. Hal itu karena Klinik Pratama sebagai organisasi pelayanan kesehatan perlu memberikan motivasi kepada seluruh pegawai agar mereka terus menjaga kinerjanya dengan mendapatkan kompensasi yang adil, proporsional, dan transparan (Koziol \& Mikos, 2020). Penilaian kinerja dapat dijadikan sebagai bahan dalam memberikan kompensasi baik finansial maupun nonfinansial, pengembangan karir pegawai, dan membangun kepuasan dan komitmen pegawai pada Klinik Pratama.

\section{SIMPULAN}

Tenaga kesehatan atau SDM kesehatan merupakan aset yang sangat penting bagi semua aspek organisasi (Kumar \& Khan, n.d.), tak terkecuali sangat berperan dalam mewujudkan keberhasilan sebuah fasilitas pelayanan kesehatan baik tingkat pertama maupun tingkat rujukan (World Health Organization, 2008). Di dalam industri pelayanan kesehatan, terdapat persaingan pasar tenaga kerja (SDM) baik yang professional maupun tidak professional dan pasar konsumen layanan kesehatan. Ada banyak faktor yang mempengaruhi keputusan SDM untuk bekerja di tempat yang mereka sukai, bertahan di tempat tersebut atau memutuskan untuk pindah ke tempat lain, demikian juga dengan 
konsumen pelayanan kesehatan atau pasien. Mereka boleh memilih fasilitas pelayanan kesehatan sesuai dengan aturan yang berlaku bagi pasien peserja JKN. Bagaimana dapat menarik SDM yang dibutuhkan KPF dan mempertahankan mereka menjadi SDM yang loyal dan berkomitmen untuk berpatisipasi dalam memajukan KPF dengan memberikan pelayanan kesehatan yang terbaik yang diperlukan dan diharapkan oleh pasien. Salah satu cara yang dilakukan oleh KPF adalah memberikan remunerasi kepada SDM nya secara adil dan layak, transparan, serta proporsional dengan cara-cara yang dapat dipertanggungjawabkan dari segi keuangan dan manajemen SDM. Penyusunan dan pengembangan sistem remunerasi Klinik Pratama Firdaus 24 Jam berdasarkan pada analis jabatan dan penilaian kinerja.

\section{UCAPAN TERIMA KASIH}

1. LP3M Universitas Muhammadiyah Yogyakarta atas kontrak penugasan program pengabdian masyarakat 2018-2019

2. Kepala Klinik Klinik Pratama 24 Jam Firdaus

3. Manajer Bidang Pelayanan Klinik Klinik Pratama 24 Jam Firdaus

\section{DAFTAR PUSTAKA}

Aggarwal, A., \& Thakur, G. S. M. (n.d.). Techniques of Performance Appraisal-A Review. 2(3), 5. Armstrong, M. (2018). Armstrong's Job Evaluation Handbook: A Guide to Achieving Fairness and Transparency in Pay and Reward. Kogan Page Publishers.

Asegid, A., Belachew, T., \& Yimam, E. (2014). Factors Influencing Job Satisfaction and Anticipated Turnover among Nurses in Sidama Zone Public Health Facilities, South Ethiopia. Nursing Research and Practice, 2014, 1-26. https:// doi.org/10.1155/2014/909768

Bednall, T. C., Sanders, K., \& Runhaar, P. (2014). Stimulating Informal Learning Activities Through Perceptions of Performance Appraisal Quality and Human Resource Management System Strength: A Two-Wave Study. Academy of Management Learning \& Education, 13(1), 45-61. https://doi.org/10.5465/amle.2012.0162

Berliana, M., Siregar, N., \& Dwi Gustian, H. (2018). The Model of Job Satisfaction and Employee Performance. International Review of Management and Marketing, 8(6). https://doi.org/ 10.32479/irmm.7183

Chang, T., Lang, J., Sun, W., Chen, J., Yu, M., Gao, W., \& Cui, H.-L. (2017). Phase Compensation Scheme for Fiber-Optic Interferometric Vibration Demodulation. IEEE Sensors Journal, 1722), 74487454. https://doi.org/10.1109/JSEN.2017.2750725

Datta, P. (2012). An applied organizational rewards distribution system. Management Decision, 503), 479-501. https://doi.org/10.1108/ 00251741211216241

Fajar, H., Yuniarsih, T., \& Ahman, E. (2018). PENGARUH PEMBERIAN PENGHARGAAN DAN HUKUMAN TERHADAP MOTIVASI KERJA SERTA IMPLIKASINYA PADA KINERJA KARYAWAN PT DIFA KREASI DI CIKARANG - BEKASI. JURNAL ILMU MANAJEMEN DAN BISNIS, 9(1). https:// doi.org/10.17509/jimb.v9i1.12979

Koziol, W., \& Mikos, A. (2020). The measurement of human capital as an alternative method of job evaluation for purposes of remuneration. Central European Journal of Operations Research, 28(2), 589-599. https://doi.org/ 10.1007/s10100-019-00629-w

Kumar, P., \& Khan, A. M. (n.d.). HUMAN RESOURCE MANAGEMENT IN PRIMARY HEALTH CARE 
SYSTEM. 12.

Lowe, G. (2012). How Employee Engagement Matters for Hospital Performance. Healthcare Quarterly, 15(2), 29-39. https://doi.org/10.12927/ hcq.2012.22915

Maslow, A. H., \& Frager, R. (1987). Motivation and personality (3rd ed). Harper and Row.

Negrut, M. L., Mihartescu, A.-A., \& Mocan, M. L. (2015). Aspects of the Internships Importance in Human Resource Training. Procedia - Social and Behavioral Sciences, 191, 308-314. https:// doi.org/10.1016/j.sbspro.2015.04.620

Prabu, A. S., \& Wijayanti, D. T. (2016). Pengaruh Penghargaan dan Motivasi Terhadap Kinerja Karyawan (Studi Pada Divisi Penjualan PT. United Motors Center Suzuki Ahmad Yani, Surabaya). Jurnal Ekonomi Bisnis dan Kewirausahaan, 5(2), 104. https://doi.org/ 10.26418/jebik.v5i2.17144

Shammot, M. (2014). The role of human resources management practices represented by employees recruitment and training and motivation for realization of competitive advantage. African Journal of Business Management, 8, 35-47. https://doi.org/10.5897/AJBM2013.7263

Waheed, A., Xiaoming, M., Karamat, J., \& Waheed, S. (2016). Comparison of Human Resource Planning and Job Analysis process in banking sector of Pakistan. Proceedings of the 2016 Joint International Information Technology, Mechanical and Electronic Engineering. 2016 Joint International Information Technology, Mechanical and Electronic Engineering Conference, Xi'an, China. https://doi.org/10.2991/ jimec-16.2016.29

World Health Organization. (2008). Operations manual for delivery of HIV prevention, care, and treatment at primary health centres in highprevalence, resource-constrained settings. http:/ /www.ncbi.nlm.nih.gov/books/NBK310908/ 